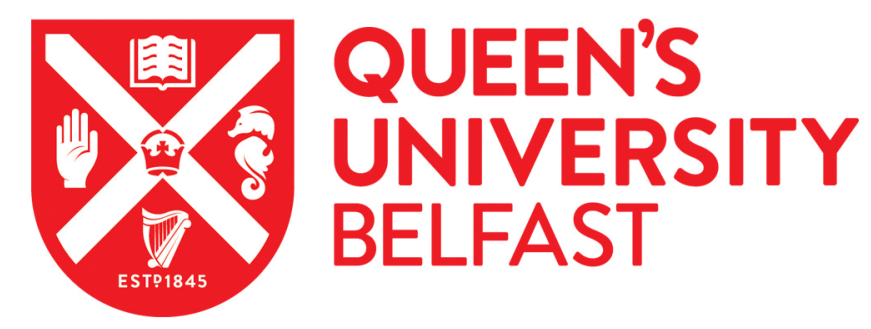

\title{
Child welfare inequalities in the four nations of the UK
}

Bywaters, P., Scourfield, J., Jones, C., Sparks, T., Elliott, M., hooper, J., McCartan, C., Shapiro, M., Bunting, L., \& Daniel, B. (2018). Child welfare inequalities in the four nations of the UK. Journal of Social Work, $20(2), 193$. https://doi.org/10.1177/1468017318793479

\section{Published in:}

Journal of Social Work

\section{Document Version:}

Peer reviewed version

Queen's University Belfast - Research Portal:

Link to publication record in Queen's University Belfast Research Portal

\section{Publisher rights}

Copyright 2018 The Authors.

This work is made available online in accordance with the publisher's policies. Please refer to any applicable terms of use of the publisher.

\section{General rights}

Copyright for the publications made accessible via the Queen's University Belfast Research Portal is retained by the author(s) and / or other copyright owners and it is a condition of accessing these publications that users recognise and abide by the legal requirements associated with these rights.

Take down policy

The Research Portal is Queen's institutional repository that provides access to Queen's research output. Every effort has been made to ensure that content in the Research Portal does not infringe any person's rights, or applicable UK laws. If you discover content in the Research Portal that you believe breaches copyright or violates any law, please contact openaccess@qub.ac.uk. 


\section{Title: Child welfare inequalities in the four nations of the UK}

Authors: Paul Bywaters ${ }^{1}$, Jonathan Scourfield ${ }^{2}$, Chantel Jones ${ }^{3}$, Tim Sparks ${ }^{3}$, Martin Elliott ${ }^{2}$, Jade Hooper ${ }^{4}$, Claire McCartan ${ }^{5}$, Marina Shapira ${ }^{4}$, Lisa Bunting ${ }^{5}$, Brigid Daniel ${ }^{6}$

1. Huddersfield University

2. Cardiff University

3. Coventry University

4. University of Stirling

5. Queen's University, Belfast

6. Queen Margaret's University, Edinburgh

Corresponding Author

Jonathan Scourfield, Cardiff School of Social Sciences, the Glamorgan Building, King Edward VII Avenue, Cardiff CF10 3WT.

Phone: $+44(0) 2920875402$

Email: Scourfield@cardiff.ac.uk

\section{Abstract}

Comparative International data on patterns of inequality in child welfare interventions, for example, the proportion of children about whom there are substantiated child protection (CP) concerns or who are in out-of-home care (CLA), are far less developed than data about inequalities in health. Few countries collect reliable, comprehensive information and definitions, methods of data collection and analysis are rarely consistent. The four UK countries (England, Northern Ireland, Scotland and Wales) provide a potential 'natural experiment' for comparing intervention patterns. This study reports on a large quantitative, descriptive study focusing on children in contact with children's services on a single date in 2015. It found that children's chances of receiving a child protection intervention was primarily related to family socio-economic circumstances, measured by neighbourhood deprivation, within all four countries and in every local area. There was a strong social gradient which was significantly steeper in some countries than others. Ethnicity was another important factor underlying inequalities. While inequalities in patterns of intervention between the four countries were considerable, they did not mirror relative levels of deprivation in the child population. Inequalities in intervention rates result from a combination of demand and supply factors. The level and extent of inequity raise profound ethical, economic and practical challenges to those involved in child protection, the wider society and the state.

Keywords:

Child protection, Child welfare, Looked after children, Out-of-home care, Inequalities, Social Gradient, Ethnicity 


\section{Child welfare inequalities in the four nations of the UK}

\section{Introduction}

In the public health field, much attention has been paid to measuring and analysing differences in mortality and morbidity between and within countries. While recognising problems in ensuring that data is genuinely comparable between and within different countries, sufficient convergence is managed through the WHO Global Health Observatory for data on over 1000 indicators of population health to be gathered from 194 countries (http://www.who.int/gho/en/). There is a substantial body of work that underpins judgements about relative rates of sickness and death and discussions of contributory causal factors. It supports a focus on understanding and combatting both underlying and more immediate causes of health inequalities (WHO, 2008). Reducing health inequalities is seen as an essential element for maximising the health of populations (Acheson, 1998; Marmot, 2010).

Some elements of a similar approach can be found for child welfare services (including family support and prevention; child protection; out-of-home care) but far less progress has been made in the key elements for an internationally comparable model. There has been limited progress in establishing agreed definitions of key concepts and even less in establishing comparable systems of data collection, analysis and reporting systems, though the socially negotiated nature of the subject under study is unlikely to be more complex than some medical categories. The epidemiology of child welfare (i.e. population-based and longitudinal studies) is far less developed internationally compared to knowledge about health inequalities. There has also been relatively little development of a discourse of inequity to account for differences in child welfare intervention rates. Reducing inequities has not secured widespread support as a policy objective for cutting levels of maltreatment, despite the WHO's report on prevention in Europe asserting that child abuse and neglect are a 'leading cause of health inequality and social injustice, with the socioeconomically disadvantaged more at risk' (Sethi et al., 2013, Foreword).

\section{Background}

\section{Child welfare - international comparisons}

To briefly summarise the international comparative evidence about child welfare inequalities, first, there are relatively few countries with consistent national systems of data collection and reporting (Thoburn, 2007; Fallon et al., 2010; Fluke \& Wulczyn, 2010; Gilbert, 2011; Kojan \& Lonne, 2012; Del Valle et al., 2013). Second, it is common for insufficient details to be presented about how data have been collected (Fallon et al., 2010). Third, there are frequently found to be problems in the quality and consistency of data collection, with protocols sometimes not followed (Thoburn, 2007) or even contested (Alastalo \& Pösö, 2014). Fourth, definitions, for example, of different categories of child abuse or neglect are not agreed internationally, with the same words sometimes being used to describe different things either over time or at a point in time (Bywaters et al., 2016a). For example, it is relatively recently that the concept of emotional abuse has emerged and forms of sexual abuse have become differentiated. Fifth, there are few established common measures of child maltreatment or system response proxies, with referrals, substantiated child protection concerns and out-of-home care all having inconsistent meanings across boundaries (Thoburn, 2007; Sethi et al., 2013). Even within-country comparisons can be problematic, but on an international basis, comparison is difficult, indeed 'limited and questionable' (Alastalo \& Pösö, 2014, p.722). The WHO review of European systems reported that 'intercountry comparisons cannot be made with any 
certainty and there is an urgent need to standardize policies, processes and registrations' (Sethi et al., 2013, p. 14).

Such evidence as there is suggests profound inequalities in children's chances of experiencing abuse and neglect and in the construction of state responses. Rates of physical maltreatment appear much higher in Eastern European states than Western countries (Gilbert et al., 2009; Sethi et al., 2013). Reports of physical abuse in the UK, USA, New Zealand, Finland, Italy and Portugal ranged from 3.7\%-16.3\%, while in Macedonia, Moldova, Latvia, Lithuania, Siberia, Russia and Romania the range was $12.2 \%-29.7 \%$. In many Western countries, rates of physical abuse have decreased in recent years in response to legislation and attitudinal change. However, definitions of maltreatment continue to evolve and expand, with new categories being included in some countries, such as exposure to domestic violence, leading to overall rates remaining relatively static (Gilbert et al., 2012).

A number of studies have examined and compared rates of out-of-home care. However, the heterogeneity of this population is considerable: age; length of stay in care; placement and the purpose of care all vary substantially, in addition to the complication of whether care is measured by point or period prevalence (Gilbert, 2011; Alastalo \& Pösö, 2014). The age profile and length of placement vary between different models of child protection systems. The Nordic countries with universal social welfare tend to place older children in out-of-home care compared to a much younger population in the UK and Australia. Movement away from paternalistic state institutional care is evident in the former communist states, but this is a slow process (Anghel, Herczog \& Dima, 2013). Child welfare policies in Spain and Italy are also moving away from institutional care, but both nations have experienced problems consolidating family foster care. Australia, Ireland, Norway and the UK have some of the highest rates of family foster care $(>80 \%)$, and Italy and Germany the lowest $(<50 \%)$. In many countries interventions involve the state placing children with relatives or friends or taking over elements of parental responsibility but without necessarily removing the child from the parents' home or from their day to day care.

There is also compelling evidence that the care system is being used for different purposes in different countries. Out-of-home care also tends in Nordic countries to be used as a family support mechanism rather than valuing permanent separation from firth parents (Forrester et al., 2009) so its social function is not the same as in the UK. Adoption is not permitted in Finland, requires birth parent permission in Sweden, and is rare in Denmark (Gilbert, 2011). Out-of-home placements in these countries are often by voluntary consent of both child and parent and regularly used to transition older teens to independent living (Gilbert, 2011; Kojan \& Lonne, 2012). The number of children adopted in the US rose by almost $50 \%$ in the years 1998-2007 which is said to account in part for a fall in out-of-home placements (Gilbert, 2011). But in England an increase in adoption has accompanied a rise in the rates of children looked after.

So, although patchy and weakened by the methodological problems identified earlier, there is consistent evidence that the responses of states and independent organisations to children and families results in very different experiences according to where you live. To put it at its most cautious it is unlikely that such inequalities simply reflect real differences in childhoods or have equally good outcomes for children and their families. There are no grounds for complacency when professions and states are implicated in systematically unequal treatment of children and parents. An important but not a sufficient step towards rectifying this situation would be the recognition of this fact and the development of an inequalities perspective.

\section{The current study and comparisons between UK nations}


The research presented in this article, funded by the Nuffield Foundation, aimed to begin the task of detailing and understanding inequalities in intervention rates by examining differences in the proportions of children on child protection plans or registers (CP), or who were 'looked after' in outof-home care (CLA), between and within the four countries of the United Kingdom (UK): England, Northern Ireland, Scotland and Wales. The UK offered the possibility of a kind of natural experiment in comparing policies and services for child protection (Bywaters et al., 2017a) although only these two types of state intervention within the wider range of provision were examined. The UK countries share a common language, government and history. However, a number of significant differences also apply. First, many powers are devolved from Westminster, the seat of the UK government, to the four individual nations. Devolution has been substantially extended in recent years with the establishment of new legislative bodies, the Scottish Parliament and the Welsh Assembly, and the power sharing agreement creating greater devolved government in Northern Ireland. Child protection policy is a devolved power and increasing differences of approach are being seen between the countries. Second, Scotland has an entirely separate legal system to that in England and Wales with different terminology and structures. The Scottish children's hearings system is unique. Third, this is just one example of different structures operating across the four countries, with children's services in Northern Ireland being managed through joint Health and Social Care Trusts rather than by elected local councils as in the three other countries. Finally, the politics of the four countries have become increasingly divergent with a different political party in power in each, at the time of writing. The Conservative party in England has to negotiate with a Labour-led government in Wales, a Scottish National Party government in Scotland and Unionist and Republican parties in Northern Ireland. Again, as devolution has grown, the political distinctiveness of the four countries has become more apparent, albeit the UK Government operates the key levers of the economy, taxation and social security policy.

Published administrative data for the four countries summarised on an annual basis by the third sector organisation, the NSPCC, and our own analysis of that published data had suggested that there were substantial differences in the proportions of children who were in out-of-home care ('children looked after') (Bentley, O'Hagan, Raff \& Bhatti, 2016; Bunting et al., 2017; McGhee et al., 2017) or subject to child protection interventions. However, the NSPCC summaries also pointed to the possibility that some of these differences were artefacts of the data collection process rather than real differences. The published data had also not controlled for key demographic and economic differences between the countries, nor had there been any comparison attempted at the local authority level, never mind any smaller geography. Previous authors had pointed to both the potential value and the practical problems inherent in comparing what was happening to children in the four nations (Munro, Brown \& Manful, 2011). Governments had responded only with publications that identified some of the problems, not with measures to ensure that published administrative data allowed readers to compare like with like.

A central intention of our research was to establish building blocks for subsequent programmes of work to identify, understand and respond to child welfare inequalities. These foundations included, first, identifying a valid basis for making like with like comparisons in intervention rates between the four countries by resolving as far as possible the differences of legislation, definition and administrative data collection; second, developing theoretical and conceptual models for examining inequalities; third, creating and testing methodological approaches - quantitative and mixed methods - for detailing inequalities and for understanding the contributory causal factors; and, fourth, changing the conversation about child welfare in the UK by establishing inequality as a key dimension of discussion. 
For differences in intervention rates to be inequalities rather than just random variations they had to meet the standard of the definition we had developed: child welfare inequity occurs when children and/or their parents face unequal chances, experiences or outcomes of involvement with child welfare services that are systematically associated with structural social disadvantage (Bywaters et al., 2015).

Current administrative systems are not designed to identify the underlying incidence or prevalence of maltreatment in the UK, so we could only investigate those children who came to the attention of state services. Several alternative measures are potentially available within those collections but difficulties in comparisons increase if period prevalence is attempted, as legislation, definitions and data collection methods have all been subject to change but at different rates and directions in different countries. We, therefore, decided to examine only the proportion of children subject to interventions on a single day - the date for annual administrative returns, $31^{\text {st }}$ March 2015 in England, Northern Ireland and Wales and the $31^{\text {st }}$ July in Scotland.

Essentially we were trying to answer this question: Are there inequalities between the four UK countries in the proportions of children who, at a point in time, are either considered to be at risk because of substantiated concerns about child protection or who are being looked after?

\section{Research methods}

This paper is concerned with one aspect of the funded study, namely the quantitative analysis of intervention rates in each UK country. The study combined administrative data of three kinds: about individual children subject to state children's services interventions, about the deprivation level of the neighbourhood and the area in which the children lived and about the child population of neighbourhoods and areas which enabled the calculation of rates of intervention. Ethical approval for the study was obtained from the Coventry University Faculty Research Ethics Committee and support secured from the Association of Directors of Children's Services in England and parallel bodies in Northern Ireland, Scotland and Wales.

Because the child populations in the four countries are of very different sizes a mixed sampling approach was adopted to ensure sufficient numbers to allow for meaningful comparison and statistical analysis. In Northern Ireland and Wales, data were requested on $100 \%$ of children who were on the Child Protection Register or who were looked after on $31^{\text {st }}$ March 2015, the census date. In England, data were collected from a representative sample of 18 LAs for the same date, including all 10 regions, and a spread of high, mid and low deprivation LAs. In Scotland, data from the $31^{\text {st }}$ July 2015 (the Scottish census date for children's services data) were sought from 10 LAs responsible for over half of all Scotland's children, including all the largest LAs by population. After data cleaning, this gave us data on over 12,000 children on Protection Plans or Registers (CP) and over 24,000 children looked after (CLA), more than $10 \%$ of all such children in the UK.

\section{Insert Table 1}

Data were collected on the children's age, gender, ethnic category, type of abuse or neglect experienced if CP, and the legal status and the current placement if CLA. In addition we asked for the small neighbourhood in which they were living or, in the case of CLA, from which they had entered care which we could link to a deprivation score.

In the UK, extraordinarily, no data are collected systematically about the parents of children involved with children's services. In order to test for the existence of a relationship between family 
circumstances and children's involvement with services, therefore, we had to use small neighbourhood deprivation scores as a proxy measure for family socioeconomic circumstances. In England and Wales, these neighbourhoods are called Lower Super Output Areas and have average total populations of around 1600, in Northern Ireland they are called Super Output Areas with populations around 2000 and in Scotland, Data Zones with average populations of around 750 . Each neighbourhood has a deprivation score based upon multiple measures but the four countries use overlapping but different measures, weighted differently, so we constructed a UK wide deprivation index following the methodology outlined by Payne and Abel (2012). This enabled us to group all UK neighbourhoods in deciles from the least deprived $10 \%$ of neighbourhoods to the most deprived.

Child population data for the small neighbourhoods were taken from the mid-year population estimates for 2014. These estimates update the comprehensive 2011 national census. Unfortunately, child population data by ethnic category and neighbourhood are not available from these mid-year estimates, so 2011 census data had to be used for the ethnicity analysis.

Data were analysed as rates per 10,000 children. Analysis was typically based on deprivation deciles, but summarised as quintiles for simplicity. Summary rates for each country were compared to deprivation decile number using Spearman rank correlation to confirm relationships. Similarly, log transformation of summary rates (to make the relationship more linear) for each country were regressed on decile number to estimate the proportional rate of increase in intervention for each decile increase in deprivation. A technical paper is available online which gives full details of the datasets and our analysis (Bywaters et al 2017b).

\section{Findings}

\section{Data gaps and comparability}

We had previously identified three main kinds of limitations in the administrative data sets currently produced by the four UK governments (Bywaters et al., 2016a, 2016b, 2017a). First, there are large gaps in the data that are collected. The two most important are that, as mentioned above, virtually no data are collected about the lives or circumstances of the parents of children subject to CP or CLA interventions and no national data are analysed or reported for levels of geography below whole LAs. There are no published data focusing on smaller geographical communities or areas. Second, some of the data collected and or reported are of dubious quality, particularly those on child disability which have had to be excluded from the analysis. Third, some of the data collected are only analysed and reported to a limited extent. The main example of this is data analysed by ethnic category.

However, two further issues of importance emerged from this comparative study. It became clear that there are complex but important differences between countries in the proportion of children defined as looked after but placed either at home with at least one parent or out-of-home with relatives or family friends. It is unclear to what extent this is primarily a matter of practice or a matter of definition. In other words, do some countries place a larger proportion of children with a parent, relative or friend than others or are there different practices in whether children living with parents or relatives or friends are counted as looked after? Table 2 shows the scale of this issue but sheds only a limited light on whether this is a real difference of practice. As can be seen, in Northern Ireland and Scotland, around a half of all CLA were placed with a parent, relative or friend. This compared to a little over a quarter of CLA in Wales and one in six in England. For a number of years up to 2014, the NSPCC annual 'How Safe Are Our Children' reports, when comparing the proportion 
of CLA in the four countries only presented data for Scotland about children who were looked after away from home but gave the data for all CLA in the other three countries. As can be seen, this approach under-estimates the complexity of comparing CLA rates between the four countries.

\section{Insert Table 2}

It is clear that there are a variety of positions taken in relation to kinship care when state services are involved, from informal arrangements acknowledged by and agreed to by children's services without formal assessment or payment, through various levels of assessment and payment to the point where relatives or friends are assessed and paid on a par with foster carers not previously known to the family. Because of these nuances and because the data available lack the detail necessary to sort between the alternatives, we decided that, for the purposes of cross-country comparisons in this study we would only use CLA data on children placed in out-of-home care who were not with parents, relatives or friends: essentially those in foster homes and residential care.

The second new issue, first identified by Bilson (private communication), is the cumulative effect of decisions to place children for adoption or on Special Guardianship Orders in England and Wales. More frequent, earlier and faster adoption of CLA has been a central plank of children's services policy in England in recent years. In England, in every year since 2000/01 more than 3000 children have left the care system to be adopted and this increased to over 4000 in 2012/13 and over 5000 in 2013/14 and 2014/15 before falling back to 4690 in 2015/16. 12\% of care leavers were adopted in $2000 / 01$ rising to $17 \%$ in $2014 / 15$. A new permanency provision, the Special Guardianship Order (SGO), was brought into effect in England and Wales on $1^{\text {st }}$ January 2006. Like adoption, it was designed to provide greater security of care for children who had been looked after either with preexisting foster carers or with relatives or friends (approximately half in each type of placement). Children on SGOs are no longer counted in statistics for looked after children. The use of SGOs increased rapidly and by 2014/15 over 3000 children in England were counted as leaving care under such orders. Cumulatively, Bilson estimates that at 31 $31^{\text {st }}$ March 2016 more than 70,000 children may be currently living in alternative families having been placed by the state through adoption or SGOs. The total is similar to the numbers of children counted as being looked after.

However, in Scotland adoption has been less a focus of policy. Proportionately, many fewer children left care because of adoption, between $3 \%$ and $7 \%$ of all care leavers between 2000/01 and $2014 / 15$. There is no Special Guardianship Order and the nearest equivalent order does not remove children from the looked after head count. Cumulatively, in the period 2002/3 to 2014/15, although the full details of age and outcome necessary for a precise calculation are not available, it looks as though approximately twice as many children, proportionately, were living in adoptive or SGO families having been placed from care in England as in Scotland.

The cumulative numbers involved are sufficiently large to have a considerable effect on comparative rates of CLA between Scotland and England and Wales. This presents both conceptual and statistical challenges. Conceptually, it has long been assumed in the UK, at least, that adoption is a totally different status to being 'in care', even if the adoption placement is made by the state. Once parental rights and responsibilities have been conferred the state no longer has a role. However, more recently there has been some blurring of this boundary with the recognition that adoptive parents may require or benefit from continuing support. The boundary is even more blurred in the case of SGOs, where local authorities are required to make available a range of support services including financial support and retain powers to be party to subsequent changes in the child's legal status. It is at least arguable that the numbers and rates of children on SGOs should be published as part of the annual CLA data returns, at least in as much detail as data on CLA and adopted children. 
Statistically, because it is not known whether or how many children on SGOs become looked after again and because of other definitional differences between England and Scotland, any calculation about the impact on CLA rates would have to involve wide confidence limits. In the case of this research, we decided not to make such calculations but to draw the issue to readers' attention. SGOs do not apply in Northern Ireland.

\section{Deprivation in the UK}

As Table 3 demonstrates, the general population of children in Northern Ireland, especially, and Wales, were much more likely to be living in higher deprivation neighbourhoods than those in England and Scotland, which had a broadly similar pattern. In all countries children are overrepresented in the most deprived $20 \%$ of neighbourhoods (Column 5 ), but the proportions in the least deprived quintile (Column 1 ) are starkly different. Close to $70 \%$ of children in Northern Ireland were living in the most deprived $40 \%$ of neighbourhoods in the UK but only a little over $40 \%$ of children in England.

LAs face radically different social-economic conditions across the UK. In eight LAs and Trusts in our sample, at least $50 \%$ of children were living in neighbourhoods amongst the most deprived $20 \%$ in the UK while in 4 LAs fewer than $15 \%$ of children did so. More than $50 \%$ of all children lived in the least deprived $20 \%$ of neighbourhoods in the UK in only one LA, but several had a third or more of their children in such places. On the other hand, two LAs had no neighbourhoods in the least deprived $40 \%$ in the UK. Given, as we outline below, the strong relationship between deprivation and intervention rates, these profound demographic differences have a major effect on demand.

\section{Insert Table 3}

\section{Similarities in Child Welfare Interventions}

Most of the variables examined showed significant differences between countries. However, gender patterns were an exception to this rule. While overall levels of intervention for males and females showed between-country inequalities, the ratio of males to females was remarkably similar. There was no statistically significant difference in the proportions of males and females on child protection plans or registers in England, Scotland and Wales (we did not have the data for Northern Ireland). There was a small but persistent difference in the proportions for CLA with a small excess (around $15 \%)$ of males in all three countries. Given the differences between boys and girls in educational attainment and in CLA rates, the apparent similarity in CP rates is remarkable and perhaps worth further exploration.

\section{Deprivation and Intervention Rates}

Within each country there is a very strong positive association, probably exponential rather than linear, between the level of neighbourhood deprivation and the proportion of children who are CLA or CP (Tables 4 and 5). This relationship is very strong and statistically significant in each country (Spearman rank correlations at decile level: all $r_{s}>0.95$, all $P<0.001$ ).

Differences between areas of high and low deprivation are not a matter of a few percentage points but multiples. A child in Scotland living in one of the most deprived $20 \%$ of UK neighbourhoods is 10 times more likely to be looked after away from parents, relatives or friends than a child in the least deprived 20\%. In England this ratio is 9:1. Small numbers in the least deprived neighbourhoods in Northern Ireland and Wales preclude a similar analysis but the broad pattern is repeated, as it is in every LA and Trust we examined. This supports the hypothesis that deprivation - a proxy for family 
socio-economic circumstances - is a primary driver of service demand in any given country or local authority.

However, differences between UK countries in overall rates cannot be explained by levels of deprivation. If deprivation was the main factor explaining inequalities in rates between countries, Northern Ireland would have the highest overall rates and England the lowest. Neither for CP nor for CLA is this the case: supply side factors are also at work, interacting with demand.

\section{Insert Table 4}

\section{Insert Table 5}

For CP, England, and Northern Ireland appear to have similar overall rates but higher than those in Scotland. The lower Scottish rates may reflect the use of Supervision Orders in which children are placed at home and not also placed on the $\mathrm{CP}$ register. For many of these children there may well be child protection concerns but they may not be recorded in the register because they are considered protected by the Order. This raises questions about the value of the register as a comprehensive record of CP concern. Another key difference is that in Scotland, almost no children aged 16 to 17 are on CP registers, unlike in the other countries (see Table 7, below). However, this does not explain the lower rates overall in Scotland which are seen in all other age groups.

The very different distribution of children by deprivation quintile in the countries means that these overall figures mask other significant differences. Although the overall CP rate in Northern Ireland is similar to that in England and Wales, Northern Ireland rates are in fact much lower in the 2 highest deprivation quintiles where two thirds of Northern Ireland children were living. The differences between countries can only be properly examined when deprivation patterns are also taken into account.

For CLA not placed with parents, relatives or friends, by contrast, Scotland has the highest rates, approximately $30 \%$ higher than those in Wales, 60\% higher than England and more than double those in Northern Ireland. The cumulative impact of differential adoption and non-kinship SGO rates may account for at least part of the difference between overall Scottish and English rates but cannot account for the stark gap between Scotland and Northern Ireland. And if children on non-kinship SGOs were counted as CLA in England and Wales, this would widen the gap between those countries and Northern Ireland. Given the costs of looked after children - the average cost in England is over $£ 50,000$ per year - these large differences could be expected to be at least as much a focus of attention for policy makers as the outcomes of placing children in care. However, with the exception of Wales (Drakeford, 2012), there is limited evidence of such concern.

Successive NSPCC How Safe Are Our Children reports have drawn attention to the gap in CLA rates between Scotland and England, although with little apparent effect on policy or practice. However, these data, while confirming that inequity, place a greater spotlight on Northern Ireland's lower rates, particularly for CLA. And it is interesting to note that Northern Ireland is the only UK country in which more children were on CP Plans than were being looked after in foster and residential care in 2015.

\section{The Social Gradient}

There is a strong social gradient affecting children's chances of a child welfare intervention: each step increase in deprivation is accompanied by a higher CLA or CP rate. There are no exceptions to this pattern between deprivation quintiles, which is also seen within individual LAs and Trusts, except in a handful of cases where numbers of children are too small to yield reliable rates. 
However, the steepness of the gradient - how much each step up in deprivation influences the CP or CLA rate - varies between countries. Using least squares regression of log transformed decile rates weighted by population numbers to calculate the slope (Table 6) reveals that, for $\mathrm{CP}$, Wales has the steepest gradient, followed by Scotland, Northern Ireland and England but only the differences between Wales and Northern Ireland and between Wales and England are statistically significant. For CLA, Wales again has the steepest gradient followed by Scotland, England and Northern Ireland. Northern Ireland has a significantly shallower gradient than all the other countries and England is significantly shallower than Wales. It is unclear why gradients differ but within an inequalities analysis flattening the slope - finding ways to reduce the impact of deprivation on intervention rates - would have a large effect on overall rates and numbers. Flattening the slope is an alternative - or possibly complementary strategy - to reducing the numbers and proportion of children subject to interventions in more deprived areas.

\section{Insert Table 6}

\section{Age}

A further dimension in which clear inequalities in children's chances of intervention between the four countries can be seen is age. As Table 7 shows, and we have already indicated, in Scotland CP interventions are essentially not used with young people aged 16 and 17 but overall Scottish rates are significantly lower across all age groups. By contrast, overall CP rates in Northern Ireland are only lower than in England and Wales for the 0-4 age group. In the 0-4 age group (Table 8), CP rates in Northern Ireland and Scotland are very similar when comparing children living in areas of similar deprivation, but in both countries rates are lower than in England and Wales.

\section{Insert Table 7}

\section{Insert Table 8}

CLA rates for children not placed with parents, relatives or friends show a consistent age pattern with one exception. Across all age groups, rates are highest in Scotland, then Wales, then England and lowest in Northern Ireland, with the exception of the 16-17 year age group. In this older group, Scottish rates are lower than those in England and Wales.

Once again, these patterns raise further questions. Overall, across the UK, at all age groups approaching one child in 100 was either on a child protection intervention or being looked after at a point in time in 2015 (Table 9). Scotland is the only country in which CLA rates fall in the oldest age group, compared to the 10-15 group, while CP interventions are essentially absent. Service patterns for 16-17 years olds compared to other age groups do appear to be different in Scotland to the other nations, perhaps reflecting the younger Scottish age of maturity: aged 16.The implications for young people who may be vulnerable require further examination. Of course, it is the outcomes of policy differences that are the central concern rather than the policy differences themselves.

\section{Insert Table 9}

\section{Ethnicity}

A much larger proportion of children in England (21\%) were identified as members of minority ethnic categories than in Scotland (6\%) or Wales (7\%) according to the 2011 Census, the latest source for which data are available at neighbourhood level. One consequence of this is that intervention rates become less reliable within some deprivation quintiles or deciles, because numbers are very small. Data on ethnicity were not available in Northern Ireland. 
As Table 10 shows, patterns of deprivation affecting children vary considerably between the 5 broad ethnic categories commonly used to present ethnicity data across the UK. In all three countries shown, Black children were very much more likely than other children to be living in the most deprived $20 \%$ of neighbourhoods: around half or more in all countries. Patterns for Mixed heritage and Asian children were more varied with apparently lower proportions living in quintile 5 in Scotland than in England or Wales. It should be borne in mind that there may be different categorisation practices across the UK.

\section{Insert Table 10}

Overall CLA rates for children not placed with parents, relatives or friends in all three countries for which numbers are sufficient show a similar pattern (Table 11). Rates for Mixed, Black and Other children are higher than those for White children but Asian children have the lowest rates by a very large margin. However, this picture looks different when controlled for deprivation. In the most deprived quintile of small neighbourhoods where the majority of Black children live (Table 12) in all 3 countries, rates for Black children are lower than those for White children. This repeats the pattern seen for the English West Midlands in 2012 (Bywaters et al., 2016c). By contrast, in the $80 \%$ of neighbourhoods that have lower deprivation (Quintiles 1 to 4; Table 13), Black children's rates are higher than those for White children. The reasons for these apparently large inequities between children in different categories and jurisdictions require further investigation. The numbers of children involved in the data presented, while always above the threshold of 10 used by the DfE in reporting data, are small outside England. The categories used and the consistency with which they are applied is a further concern. Whether low rates for children in minority ethnic categories reflect better childhoods or the differential reach of services is unknown. And whether apparently higher rates for minority category children in low deprivation neighbourhoods (which are also less ethnically diverse) reflects discrimination in service delivery or pressures arising from greater isolation is also unknown. What the data do confirm is the complex interaction of supply and demand, of national and local service delivery priorities, policies and patterns and children's unequal experiences in different communities. Further analysis of the ethnicity data will be published separately.

\section{Insert Table 11}

\section{Insert Table 12}

\section{Insert Table 13}

\section{Limitations of the Study}

A number of cautionary points about the study have been noted already. Two major factors should be particularly borne in mind. The first is the consequence of no data being collected about the circumstances, identities or backgrounds of the children's parents or the households from which the children come. Using neighbourhood deprivation scores as a proxy for family socio-economic circumstances is a widely adopted approach but it is not certain that the families in contact with children's social services are representative of the neighbourhoods in which they live. Furthermore, the construction of the UK wide deprivation index relies heavily on two key indicators: income and employment, rather than a wider range of factors, such as the neighbourhood environment or the health of the population which may be of significance. However, deprivation scores are only used to judge the relative positions of neighbourhoods and LAs and tests of alternative deprivation measures within countries suggests a high level of congruence whatever particular measures are used. 
Second, securing comparability of the data between countries is complex. As we have outlined, while the term 'looked after' is employed in all the four countries, very different patterns in its application - for example, in the proportion of CLA who are placed with parents, relatives or friends - are apparent. Our headline measure of CLA, which only compares children in foster or residential care, is weakened by the exclusion of children in England and Wales who are on Special Guardianship Orders, around half of whom are living with adults who were previously their foster carers (but of whom an unknown number may, in fact, be relatives or friends). It is also impossible to judge, because no data exist, exactly how many informal arrangements are being made for relatives and friends to be involved in the care of children where the state is involved in the negotiation but there is no monetary or legal transaction.

It is also unfortunate, to say the least, that data on childhood disability (and health) are so unreliable that they have been excluded from this analysis.

\section{Conclusions}

Despite these important limitations, we would argue that it is reasonable to reach a number of key conclusions. There are large structural inequalities in children's chances of being on a child protection plan or register or being in out-of-home care which relate to where the child's family lives. Within all the four countries there is a strong social gradient. Children's chances of state intervention are patterned by their family or household circumstances measured by neighbourhood deprivation. This has a major impact on service demand. This is true at different ages and for both boys and girls. These inequalities are very large: children in the most deprived $10 \%$ of neighbourhoods in the UK are over ten times more likely to be subject to an intervention than children in the least deprived $10 \%$. The steepness of the social gradient varies between countries but is ever present. Demand factors affecting childhoods are fundamental to child protection rates. It is clear that children's services interventions reflect social inequalities. It is unclear whether those interventions reduce or exacerbate inequalities affecting children and their parents.

However, inequalities in overall intervention rates between countries do not reflect the relative levels of deprivation affecting children. Broadly speaking, Northern Ireland, which has the highest levels of deprivation, has the lowest intervention rates. Scotland, with apparently similar deprivation patterns to England, appears to have higher rates of CLA but lower rates of CP. The relative use of child protection plans or registers compared to foster and residential care is very different in the different countries. In Scotland something like 3 times as many children are in out-of-home care as on the child protection register. In England and Wales CLA rates are roughly $20 \%$ and $30 \%$ higher than CP rates, respectively, but in Northern Ireland CP rates are higher than CLA rates. So supply factors are also important. The balance of emphasis within policy and service provision between family and community support, child protection investigation and substantiation, out-of-home care, kinship care, guardianship and adoption vary substantially between the four countries. Data on expenditure are not transparent and cannot currently be reliably compared but are likely to be important (Webb \& Bywaters, 2018).

Third, inequalities between children in different ethnic categories are also profound. Comparing rates between ethnic categories makes little sense unless deprivation is taken into account because of the very substantial social inequalities that exist between ethnic groups in the UK. Black children, including Black Caribbean children whose families have been here for generations in most cases, are significantly disadvantaged economically - if the measure of neighbourhood deprivation is an accurate proxy. This appears to be reflected in CLA rates that, overall, are higher than rates for White children. However, for children of Pakistani and Bangladeshi origin, whose families are even 
more deprived on average (Corlett, 2017), intervention rates are relatively low so the relationships at work are clearly complex. But for rates to differ by a factor of five, as they do between Asian and White children in the most deprived $20 \%$ of neighbourhoods, is extraordinary. At very least, this requires proper understanding as to whether children are being better cared for or whether services are failing to reach children in need. If some communities do have a lower incidence of abuse and neglect, is there a model here for a different approach to supporting and protecting children?

Fourth, while there are clearly structural inequalities of demand and supply between and within countries, there are also substantial variations in policy or practice between local authorities operating in the same jurisdiction. We have reported elsewhere that these may be partly related to levels of expenditure relative to demand (Bywaters et al., 2015; Webb \& Bywaters, 2018) and so themselves reflective of patterns of deprivation. But other factors in the priorities, approaches, and cultures of local services must also be at work, as others have reported previously (Oliver, Owen, Statham \& Moss, 2001; Dickens, Howell, Thoburn \& Schofield, 2005).

These inequities in children's services intervention rates have profound implications for children and their parents. We estimate that if CLA rates in England, controlling for deprivation, were the same as in Northern Ireland, around 40\% fewer English children would be living apart from their parents in foster or residential care with cost savings approaching $20 \%$ of the total children's services budget. Of course, currently, a further weakness in family policy internationally is that there is no clear measure of the 'right' proportion of children who should be in out-of-home care. Recently studies in the UK have provided some evidence that being placed in out-of-home care can lead to better outcomes for children, compared to children in need who remain at home or looked-after children who return home (Forrester \& Harwin, 2008; Ward, Brown \& Westlake, 2012; Sebba et al., 2015). However, none of these studies have controlled for the comparatively advantaged socio-economic circumstances of foster families, including the financial support provided by the state which is not available to birth families.

This comparison of the four UK countries raises profound ethical challenges to everyone with a role in policy, practice, education or research relating to child protection and family support. Whether the rates of intervention in some places, or with some groups, are 'too low' or 'too high', the degree of disparity in the lives of children and their families that are represented in these data cannot reflect social justice. The injustice in children's chances of a safe, supportive and stimulating childhood living consistently with one or more of their birth parents reflects a combination of the inequitable conditions in which children are being brought up and inequitable service responses to children. The injustice is compounded by the evidence of ethnic inequities. The challenge faced by politicians, policy makers and practitioners is made more difficult by the paucity of systematic information about the parents and the home circumstances of children in contact with services or about the role of poor health and disability. The absence of agreed measures of appropriate intervention rates is a further indictment of the current state of play. And this takes place in the context of insufficient knowledge about the short and long term costs of alternative approaches to child protection and family support or about their outcomes.

Finally, this evidence about child protection is indicative of the most acute impacts of social inequalities on children and on their parents. While those directly involved with children's services have an obligation to face these facts and question the patterns and trends of current policy and practice, children's services alone cannot be expected to resolve the underlying structural fault lines in UK society visible in so many areas of social, economic and environmental policy. 


\section{Research Ethics}

Ethical approval for the study was obtained from the Coventry University Faculty Research Ethics Committee and support secured from the Association of Directors of Children's Services in England and parallel bodies in Northern Ireland, Scotland and Wales.

\section{Funding}

The authors wish to acknowledge the support of the Nuffield Foundation which funded the work reported here (grant reference: KID 41935). The Nuffield Foundation is an endowed charitable trust that aims to improve social well-being in the widest sense. It funds research and innovation in education and social policy and also works to build capacity in education, science and social science research. The views expressed are those of the authors and not necessarily those of the Foundation. More information is available at www.nuffieldfoundation.org

\section{References}

Acheson, D. (1998). Independent inquiry into inequalities in health: Report. London: The Stationery Office. Retrieved from https://assets.publishing.service.gov.uk/government/uploads/system/uploads/attachment data/file/265503/ih.pdf

Alastalo, M., \& Pösö, T. (2014). Number of children placed outside the home as an indicator - social and moral implications of commensuration. Social Policy \& Administration, 48(7), 721-738. http://doi.org/10.1111/spol.12073

Anghel, R., Herczog, M., \& Dima, G. (2013). The challenge of reforming child protection in Eastern Europe: the cases of Hungary and Romania. Psychosocial Intervention, 22(3), 239-249. http://doi.org/10.5093/in2013a27

Bentley, H., O’Hagan, O., Raff, A., \& Bhatti, I. (2016). How safe are our children? The most comprehensive overview of child protection in the UK. London: NSPCC. Retrieved from https://www.nspcc.org.uk/globalassets/documents/research-reports/how-safe-children2016-report.pdf

Bunting, L., McCartan, C., McGhee, J., Bywaters, P., Daniel, B., Featherstone, B., \& Slater, T. (2017). Trends in child protection across the UK: A comparative analysis. The British Journal of Social Work, bcx102. https://doi.org/10.1093/bjsw/bcx102

Bywaters, P., Brady, G., Sparks, T., Bos, E., Bunting, L., Daniel, B. ... Scourfield, J. (2015). Exploring inequities in child welfare and child protection services: Explaining the 'inverse intervention law'. Children and Youth Services Review, 57, October, 98-105. https://doi.org/10.1016/j.childyouth.2015.07.017

Bywaters, P., Bunting, L., Davidson, G., Hanratty, J., Mason, W., McCartan, C. \& Steils, N. (2016a). The relationship between poverty, child abuse and neglect: An evidence review. York: Joseph Rowntree Foundation. Retrieved from https://www.jrf.org.uk/report/relationship-betweenpoverty-child-abuse-and-neglect-evidence-review

Bywaters, P., Brady, G., Sparks, T., \& Bos, E. (2016b). Child welfare inequalities: new evidence, further questions. Child and Family Social Work, 21, 369-80.

https://doi.org/10.1111/cfs.12154 
Bywaters, P., Kwhali, J., Brady, G., Sparks, T. \& Bos, E. (2016c). Out of sight, out of mind: Ethnic inequalities in child protection and out-of-home care intervention rates. The British Journal of Social Work, 47(7), 1884-1902. https://doi.org/10.1093/bjsw/bcw165

Bywaters, P., Brady, G., Bunting, L., Daniel, B., Featherstone, B., Jones, C. ... Webb, C. (2017a). Inequalities in English child protection practice under austerity: a universal challenge? Child and Family Social Work, 23(1). https://doi.org.10.1111/cfs.12383

Bywaters, P., Brady, G., Jones, C., Sparks, T., McCartan, C., Bunting, L. ... Scourfield, J. (2017) Identifying and Understanding Inequalities in Child Welfare Intervention Rates: Quantitative Methodology Technical Paper. Coventry, Coventry University, Retrieved from https://www.coventry.ac.uk/Global/08\%20New\%20Research\%20Section/Child\%20Welfare \%20Inequalities\%20Project\%20-\%20Technical\%20Paper.docx

Corlett, A. (2017). Diverse outcomes. Living standards by ethnicity. London: Resolution Foundation. Retrieved from http://www.resolutionfoundation.org/app/uploads/2017/08/Diverseoutcomes.pdf

Del Valle, J. F., Canali, C., Bravo, A., \& Vecchiato, T. (2013). Child protection in Italy and Spain: Influence of the family supported society. Psychosocial Intervention, 22(3), 227-237. https://doi.org/10.5093/in2013a26

Dickens, J., Howell, D., Thoburn, J., \& Schofield, G. (2005). Children starting to be looked after by local authorities in England: An analysis of inter-authority variation and case-centred decision making. The British Journal of Social Work, 37(4), 597-617. http://doi.org/10.1093/bjsw/bch276

Drakeford, M. (2012). Number of children in care increasing at a greater rate in Wales than England [online article]. Retrieved from http://www.clickonwales.org/2012/11/far-more-welsh-thanenglish-children-in-care/

Fallon, B., Trocmé, N., Fluke, J., MacLaurin, B., Tonmyr, L., \& Yuan, Y-Y. (2010). Methodological challenges in measuring child maltreatment. Child Abuse and Neglect, 34(1), 70-79. http://doi.org/10.1016/j.chiabu.2009.08.008

Featherstone, B., Morris, K., Daniel, B., Bywaters, P., Brady, G. ... Mirza, N. (2017). Poverty, inequality, child abuse and neglect: Changing the conversation in child protection? Children and Youth Services Review. https://doi.org/10.1016/j.childyouth.2017.06.009

Fluke, J. D., \& Wulczyn, F. (2010). A concept note on child protection systems monitoring and evaluation. New York: UNICEF. Retrieved from https://www.unicef.org/protection/Concept Note on Child Protection revised $160710 \mathrm{fi}$ nal2.pdf

Forrester, D., Goodman, K., Cocker, C., Binnie, C., \& Jensch, G. (2009). What is the impact of public care on children's welfare? A review of research findings from England and Wales and their policy implications. Journal of Social Policy, 38(3), 439-456. http://doi.org/10.1017/S0047279409003110

Forrester, D., \& Harwin, J. (2008). Parental substance misuse and child welfare: Outcomes for children two years after referral. The British Journal of Social Work, 38(8), 1518-1535. http://doi.org/10.1093/bjsw/bcm051 
Gilbert, N. (2011). A comparative study of child welfare systems: abstract orientations and concrete results. Children and Youth Services Review, 34(3), 532-536.

http://doi.org/10.1016/j.childyouth.2011.10.014

Gilbert, R., Widom, C. S., Browne, K., Fergusson, D., Webb, E., \& Janson, S. (2009). Burden and consequences of child maltreatment in high-income countries. The Lancet, 373(9657), 6881. http://doi.org/10.1016/S0140-6736(08)61706-7

Gilbert, R., Fluke, J., O’Donnell, M., Gonzalez-Izquierdo, A., Brownell, M., Gulliver, P. \& Sidebotham, P. (2012). Child maltreatment: Variation in trends and policies in six developed countries. The Lancet, 379(9817), 758-72. http://doi.org/10.1016/S0140-6736(11)61087-8

Kojan, B. H., \& Lonne, B. (2012). A comparison of systems and outcomes for safeguarding children in Australia and Norway. Child \& Family Social Work, 17(1), 96-107. http://doi.org/10.1111/j.1365-2206.2011.00776.x

Marmot, M. G., Allen, J., Goldblatt, P., Boyce, T., McNeish, D., Grady, M., \& Geddes, I. (2010). Fair society, healthy lives: Strategic review of health inequalities in England post-2010. London: The Marmot Review. Retrieved from https://www. parliament.uk/documents/fair-societyhealthy-lives-full-report.pdf

McGhee, J., Bunting, L., McCartan, C., Elliott, M., Bywaters, P. \& Featherstone, B. (2017). Looking after children in the UK - convergence or divergence? The British Journal of Social Work, bcx103. https://doi.org/10.1093/bjsw/bcx103

Munro, E. R., Brown, R., \& Manful, E. (2011). Safeguarding children statistics: The availability and comparability of data in the UK. (Department for Education Research Brief DFE-RB153). London: Department for Education. Retrieved from https://assets.publishing.service.gov.uk/government/uploads/system/uploads/attachment data/file/181224/DFE-RB153.pdf

Oliver, C., Owen, C., Statham, J., \& Moss, P. (2001). Figures and facts: Local authority variance on indicators concerning child protection and children looked after. London: Thomas Coram Research Unit, Institute of Education, University of London. Retrieved from http://discovery.ucl.ac.uk/1482310/1/Oliver2001figuresandfacts.pdf

Payne, R. \& Abel, G. (2012). UK indices of multiple deprivation - a way to make comparisons across constituent countries easier. Health Statistics Quarterly 53, 22-37.

Sebba, J., Berridge, D., Luke, N., Fletcher, J., Bell, K., Strand, S. ... O'Higgins, A. (2015). The educational progress of looked after children in England: Linking care and educational data. Oxford: The Rees Centre. Retrieved from https://ora.ox.ac.uk/objects/uuid:49b64928-48084898-911c30e8981b2ffb/download file?file format=pdf\&safe filename=EducationalProgressLookedA fterChildrenOverviewReport Nov2015.pdf\&type of work=Report

Sethi, D., Bellis, M., Hughes, K., Gilbert, R., Mitis, F. \& Galea, G. (2013). European report on preventing child maltreatment European report on preventing child maltreatment. Geneva: World Health Organization. Retrieved from http://www.euro.who.int/ data/assets/pdf file/0019/217018/European-Report-onPreventing-Child-Maltreatment.pdf?ua $=1$ 
Thoburn, J. (2007). Globalisation and child welfare: Some lessons from a cross-national study of children in out-of-home care. Norwich: University of East Anglia. Retrieved from http://www.google.co.uk/url?sa=t\&rct=j\&q=\&esrc=s\&source=web\&cd=1\&ved=0ahUKEwjRo c2Vv bbAhUFdcAKHeKvANYQFggpMAA\&url=http\%3A\%2F\%2Fwww.crin.org\%2Fen\%2Fdocs \%2FMonograph3.doc\&usg=AOvVaw3OAfHSSVwXAsIGhOkfR t7

Ward, H., Brown, R., \& Westlake, D. (2012). Safeguarding babies and very young children from abuse and neglect. London: Jessica Kingsley Publishers.

Webb, C. \& Bywaters, P. (2018). Austerity, rationing and inequity: Trends in children's \& young peoples' services expenditure in England between 2010 and 2015. Local Government Studies, 44(3), 391-415. https://doi.org/10.1080/03003930.2018.1430028

WHO. (2008). Closing the gap in a generation: health equity through action on the social determinants of health: Commission on Social Determinants of Health Final Report. Geneva: World Health Organization. 
Table 1: Child and local authority sample sizes for UK comparative study.

\begin{tabular}{|l|c|c|c|}
\hline Country & Number of LAs* & $\begin{array}{l}\text { Children on Child } \\
\text { Protection Plans } \\
\text { or Registers }\end{array}$ & $\begin{array}{l}\text { Children Looked } \\
\text { After }\end{array}$ \\
\hline England & $\mathbf{1 8}$ & $\mathbf{6 3 1 0}$ & $\mathbf{8 0 9 0}$ \\
\hline $\mathbf{N I}$ & $\mathbf{5}$ & $\mathbf{1 8 4 5}$ & $\mathbf{2 8 7 8}$ \\
\hline Scotland & 10 & $\mathbf{1 4 1 0}$ & $\mathbf{8 4 1 8}$ \\
\hline Wales & $\mathbf{2 2}$ & $\mathbf{2 8 4 7}$ & $\mathbf{5 0 9 1 * *}$ \\
\hline Total & $\mathbf{5 5}$ & $\mathbf{1 2 4 1 2}$ & $\mathbf{2 4 4 7 7}$ \\
\hline *Health and Social Care Trusts in NI \\
\hline $\begin{array}{l}\text { ** High levels of missing neighbourhood data in 2 Welsh LAs meant that they } \\
\text { were excluded from this analysis. }\end{array}$
\end{tabular}


Table 2: Percentage of all looked after children placed at home or with relatives or friends, by UK country, 2015.

\begin{tabular}{|l|c|c|c|}
\hline & $\begin{array}{l}\text { At home with a } \\
\text { parent }\end{array}$ & $\begin{array}{l}\text { Placed with a } \\
\text { relative or friend }\end{array}$ & Total \\
\hline England & 5 & 11 & 16 \\
\hline NI & 16 & 31 & 47 \\
\hline Scotland & 23 & 29 & 52 \\
\hline Wales & 11 & 16 & 27 \\
\hline
\end{tabular}


Table 3: Distribution of child population (0-17; percentages) by neighbourhood deprivation quintile, UK countries, 2014 mid year estimates.

\begin{tabular}{|l|c|c|c|c|c|}
\hline & \multicolumn{5}{|c|}{ Deprivation Quintile (1 = least deprived) } \\
\hline & 1 & 2 & 3 & 4 & 5 \\
\hline England & 20 & 19 & 19 & 18 & 24 \\
\hline NI & 1 & 13 & 19 & 31 & 37 \\
\hline Scotland & 19 & 19 & 18 & 17 & 26 \\
\hline Wales & 7 & 16 & 24 & 26 & 26 \\
\hline
\end{tabular}


Table 4: CP rates per 10,000 children by deprivation quintile and overall, adjusted, UK countries, 2015.

Numbers of children in NI living in the least deprived $20 \%$ of UK neighbourhoods are too small for rates to be reliable.

\begin{tabular}{|c|c|c|c|c|c|c|}
\hline & \multicolumn{5}{|c|}{ Deprivation quintiles (1 = least deprived) } & \multirow[b]{2}{*}{ ALL } \\
\hline & 1 & 2 & 3 & 4 & 5 & \\
\hline England & 12 & 23 & 36 & 52 & 100 & 47 \\
\hline NI & & 14 & 23 & 37 & 68 & 43 \\
\hline Scotland & 4 & 9 & 21 & 25 & 57 & 26 \\
\hline Wales & 5 & 11 & 26 & 47 & 94 & 45 \\
\hline
\end{tabular}


Table 5: CLA not with parents, relatives or friends by deprivation quintile and overall, rate per 10,000 children, adjusted, UK countries, 2015.

Numbers of children in NI living in the least deprived $20 \%$ of UK neighbourhoods are too small for rates to be reliable.

\begin{tabular}{|c|c|c|c|c|c|c|}
\hline & \multicolumn{5}{|c|}{ Deprivation quintiles (1 = least deprived) } & \multirow[b]{2}{*}{ ALL } \\
\hline & 1 & 2 & 3 & 4 & 5 & \\
\hline England & 13 & 26 & 35 & 61 & 112 & 52 \\
\hline NI & & 17 & 29 & 31 & 48 & 35 \\
\hline Wales & 10 & 19 & 35 & 57 & 135 & 62 \\
\hline Scotland & 18 & 34 & 45 & 82 & 188 & 82 \\
\hline
\end{tabular}


Table 6: The social gradient. Average increase in intervention rates for each increase in deprivation decile.

\begin{tabular}{|l|c|c|}
\hline & CP & CLA \\
\hline England & $29 \%$ & $29 \%$ \\
\hline NI & $31 \%$ & $18 \%$ \\
\hline Scotland & $37 \%$ & $33 \%$ \\
\hline Wales & $46 \%$ & $38 \%$ \\
\hline
\end{tabular}


Table 7: CP and CLA rates by age group, UK countries, 2015

\begin{tabular}{|l|c|c|c|c|}
\hline CP Rates & England & NI & Scotland & Wales \\
\hline 0 to 4 & 61 & 54 & 42 & 66 \\
\hline 5 to 9 & 48 & 48 & 28 & 46 \\
\hline 10 to 15 & 36 & 37 & 18 & 37 \\
\hline 16 to 17 & 12 & 19 & 1 & 15 \\
\hline CLA Rates & England & NI & Scotland & Wales \\
\hline 0 to 4 & 29 & 25 & 49 & 35 \\
\hline 5 to 9 & 34 & 27 & 63 & 43 \\
\hline 10 to 15 & 60 & 39 & 103 & 79 \\
\hline 16 to 17 & 96 & 67 & 86 & 100 \\
\hline
\end{tabular}


Table 8: CP rates, age 0-4, by deprivation quintile, UK countries, 2015.

Numbers of children in $\mathrm{NI}$ living in the least deprived $20 \%$ of UK neighbourhoods are too small for rates to be reliable.

\begin{tabular}{|l|c|c|c|c|c|c|}
\hline & \multicolumn{5}{|c|}{ Deprivation quintiles (1 = least deprived) } & \\
\hline & 1 & 2 & 3 & 4 & 5 & All \\
\hline England & 14 & 31 & 47 & 67 & 120 & 61 \\
\hline NI & & 10 & 26 & 44 & 91 & 54 \\
\hline Scotland & 7 & 15 & 29 & 41 & 90 & 42 \\
\hline Wales & 5 & 18 & 38 & 59 & 134 & 66 \\
\hline
\end{tabular}


Table 9: Combined CPP and CLA rates, by age group, UK countries

\begin{tabular}{|l|c|c|c|c|}
\hline & England & NI & Scotland & Wales \\
\hline 0 to 4 & 90 & 78 & 91 & 101 \\
\hline 5 to 9 & 82 & 76 & 91 & 90 \\
\hline 10 to 15 & 96 & 77 & 121 & 117 \\
\hline 16 to 17 & 107 & 86 & 86 & 114 \\
\hline
\end{tabular}


Table 10: Percentage of all children living in quintile 5 by ethnic category and country, 2011 census.

\begin{tabular}{|l|c|c|c|c|c|}
\hline & White & Mixed & Asian & Black & Other \\
\hline England & 20 & 33 & 31 & 49 & 35 \\
\hline Scotland & 26 & 20 & 26 & 59 & 33 \\
\hline Wales & 25 & 32 & 39 & 55 & 36 \\
\hline
\end{tabular}


Table 11: Overall CLA rates by ethnic group and country, 2015

\begin{tabular}{|l|c|c|c|c|c|}
\hline & White & Mixed & Asian & Black & Other \\
\hline England & 49 & 73 & 17 & 67 & 61 \\
\hline Scotland & 76 & 183 & 24 & 104 & 203 \\
\hline Wales & 58 & 89 & 27 & 74 & 59 \\
\hline
\end{tabular}


Table 12: CLA rates in Quintile 5 (most deprived), by ethnic category and country

\begin{tabular}{|l|c|c|c|c|c|}
\hline & White & Mixed & Asian & Black & Other \\
\hline England & 127 & 117 & 23 & 71 & 87 \\
\hline Scotland & 179 & 545 & 61 & 144 & 360 \\
\hline Wales & 131 & 187 & 47 & 65 & 87 \\
\hline
\end{tabular}


Table 13: CLA rates in Quintiles 1-4 (least deprived), by ethnic category and country

\begin{tabular}{|l|c|c|c|c|c|}
\hline & White & Mixed & Asian & Black & Other \\
\hline England & 30 & 51 & 14 & 63 & 46 \\
\hline Scotland & 41 & 90 & 11 & 47 & 127 \\
\hline Wales & 34 & 44 & 14 & 84 & 43 \\
\hline
\end{tabular}

